\title{
Smoking-related interstitial lung diseases: a concise review
}

\author{
J.H. Ryu*, T.V. Colby", T.E. Hartman ", R. Vassallo*
}

\begin{abstract}
Smoking-related interstitial lung diseases: a concise review. J.H. Ryu, T.V. Colby, T.E. Hartman, R. Vassallo. (C) ERS Journals Ltd 2001.

ABSTRACT: Interstitial lung diseases (also known as diffuse infiltrative lung diseases) are a heterogeneous group of parenchymal lung disorders of known or unknown cause. These disorders are usually associated with dyspnoea, diffuse lung infiltrates, and impaired gas exchange. The majority of interstitial lung diseases are of unknown cause. Known causes of interstitial lung disease include inhalation of organic and inorganic dusts as well as gases or fumes, drugs, radiation, and infections.

This review summarizes the clinical, radiological, and histopathological features of four interstitial lung disorders that have been linked to smoking. These disorders include desquamative interstitial pneumonia, respiratory bronchiolitis-associated interstitial lung disease, pulmonary Langerhans' cell histiocytosis, and idiopathic pulmonary fibrosis. Available evidence suggests most cases of desquamative interstitial pneumonia, respiratory bronchiolitis-associated interstitial lung disease, and pulmonary Langerhans' cell histiocytosis are caused by cigarette smoking in susceptible individuals. Smoking cessation should be a main component in the initial therapeutic approach to smokers with these interstitial lung diseases. In addition, smoking appears to be a risk factor for the development of idiopathic pulmonary fibrosis.

Eur Respir J 2001; 17: 122-132.
\end{abstract}

*Division of Pulmonary and Critical Care Medicine, "Dept of Diagnostic Radiology, Mayo Clinic Rochester, MN, USA, and " Dept of Laboratory Medicine and Pathology, Mayo Clinic Scottsdale, AZ, USA.

Correspondence: J.H. Ryu, Division of Pulmonary and Critical Medicine, Desk East 18, Mayo Clinic, 55905 Rochester, MN, USA.

Fax: 15072664372

Keywords: Bronchiolitis, interstitial lung diseases, Langerhans' cell histiocytosis, pulmonary fibrosis, smoking

\section{Received: April 102000}

Accepted after revision August 182000

This review was supported by funding from the Mayo foundation.
Cigarette smoking is very costly to both the individual and society. Half of all cigarette smokers will eventually be killed by their habit [1]. Smoking remains the most preventable cause of premature death and morbidity in the US and the developed world [1,2]. Cigarette smoke is a complex mixture of more than 4,000 compounds and causes a variety of pulmonary and systemic effects in humans [1-3]. Cigarette smoking is the major cause of lung cancer, which in turn is the leading cause of cancer deaths in both males and females in the USA $[1,2]$. In addition, cigarette smoking is the principal risk factor for developing chronic obstructive pulmonary disease (COPD). An estimated $10-15 \%$ of all smokers develop clinically significant airflow obstruction [1]. Recently, smoking has been implicated in causing interstitial lung disease.

Interstitial lung diseases (ILDs) or diffuse infiltrative lung diseases represent a heterogeneous group of lung disorders of known or unknown cause, generally characterized by dyspnoea, diffuse parenchymal lung infiltrates, restrictive pulmonary dysfunction, and impaired gas exchange [4-8]. The most common ILDs include idiopathic pulmonary fibrosis (IPF), sarcoidosis, pneumoconioses, and those associated with connective tissue diseases [4-8]. It has recently been appreciated that cigarette smoking is related to the development of several ILDs including desquamative interstitial pneumonia (DIP), respiratory bronchiolitisassociated interstitial lung disease (RBILD), pulmonary Langerhans' cell histiocytosis (PLCH), and IPF. In this article, the authors will review the clinical, radiological, and histopathological features of these lung disorders as well as their relationship to smoking.

\section{Methods}

The authors searched the MEDLINE database for literature published from 1966 to 1999. The Medical subject headings (MeSH) terms smoking and lung, lung diseases, interstitial lung diseases, bronchiolitis, Langerhans' cell histiocytosis and pulmonary fibrosis were used in separate searches, and studies found during each search were combined. Limits were set for English language only. The authors identified additional relevant studies by manually searching bibliographies of retrieved articles. The primary criterion for including studies in this review was based on the authors judgment regarding their relevance to the clinician involved in the care of patients with lung diseases, as well as their quality.

\section{Desquamative interstitial pneumonia}

DIP is currently classified as a form of idiopathic interstitial pneumonia [9]. The most striking histopathologic finding in DIP (fig. 1) is the presence of increased numbers of pigmented macrophages evenly dispersed within alveolar spaces [6, 9]. The overall 


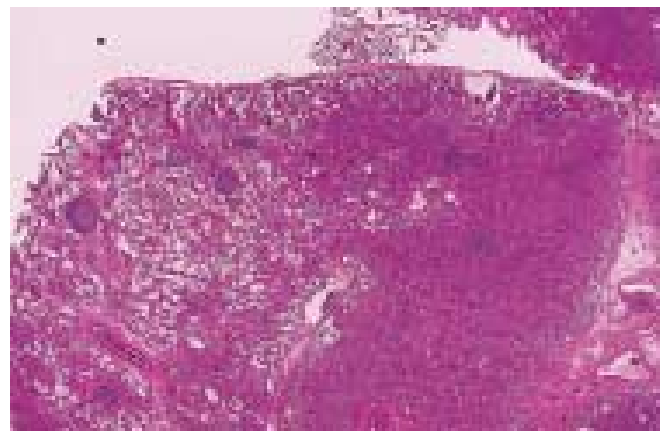

c)

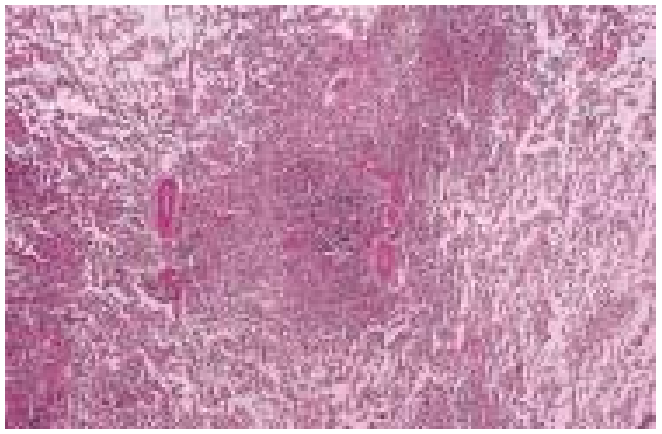

e)

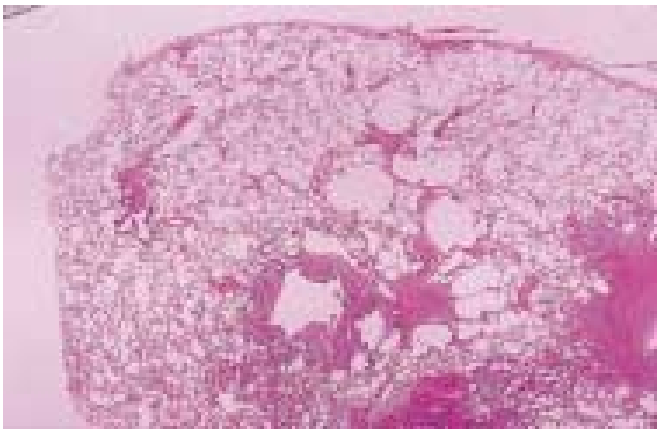

g)

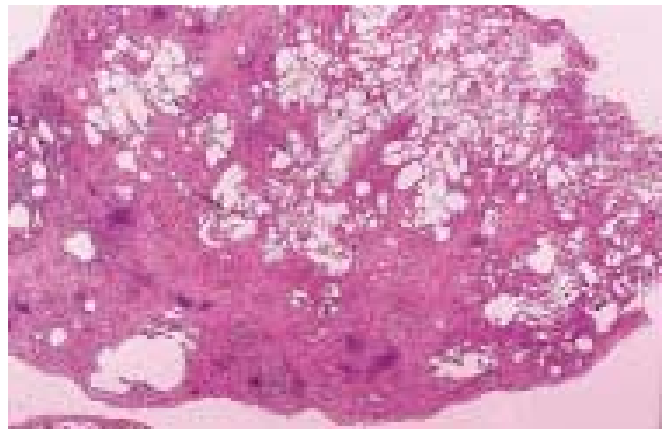

b)

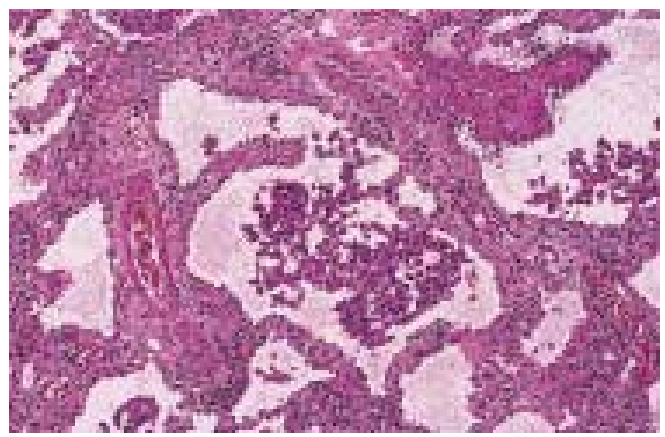

d)

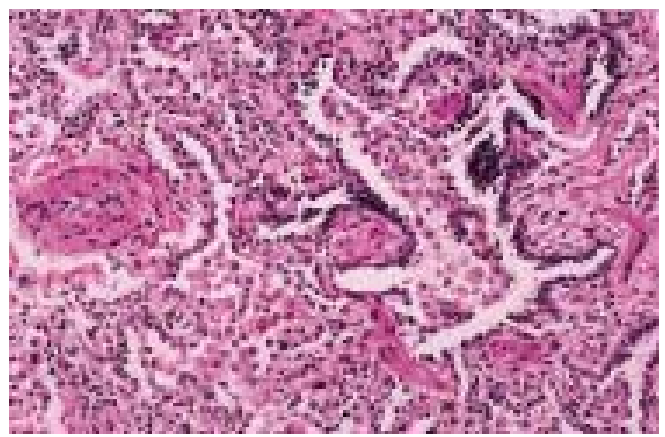

f)

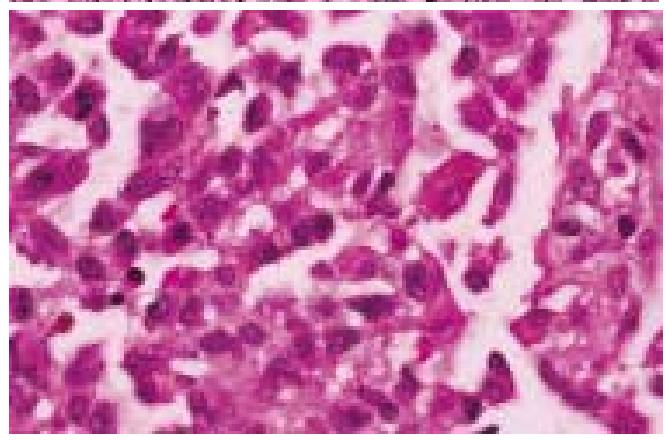

h)

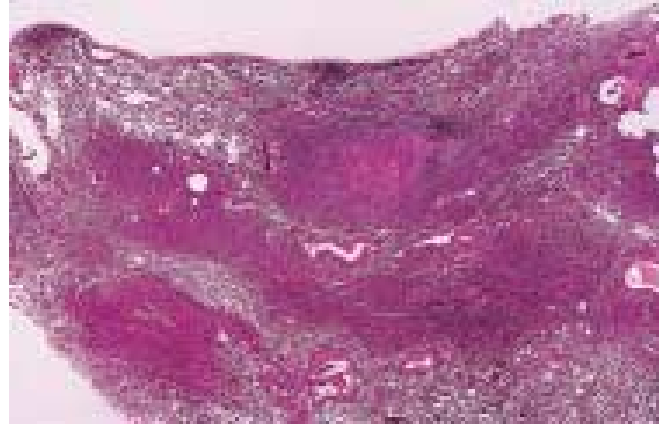

Fig. 1. - Histological features of smoking-related interstitial lung diseases. a) Low-power view of desquamative intersitial pneumonia (DIP) showing relatively diffuse involvement of the lung tissue with scattered germinal centres. To the right, the midly atelectatic lung tissue appears somewhat solid, whereas the airspaces are more apparent at left and show a prominent filling by macrophages. b) Highpower view of DIP showing marked increase in alveolar macrophages and mild alveolar septal thickening and fibrosis. c) Low-power view of respiratory bronchiolitis-associated interstitial lung disease (RBILD) showing a prominent collection of intra-alveolar macrophages that centres on a bronchiole and alveolar duct. d) High-power view of RBILD showing marked increase in alveolar macrophages and mild alveolar septal thickening and fibrosis. e) Low-power view of pulmonary Langerhans' cell histiocytosis (PLCH) showing two lesion (lower centre), one of which shows central cavitation and the other (to the right of the first) showing central pink fibrosis and stellate character. The surrounding lung tissue shows emphysematous change and an additional lesion (far right). The presence of active cellular lesions (left centre) as well as old healed lesions of pulmonary LCH (right centre) is not uncommon. f) Highpower view of PLCH showing numerous Langerhans' cells with their distinctive folded and delicate nuclei. A pigmented alveolar macrophage with its oval nucleus and denser tan cytoplasm is also present (right centre). g) Low-power view of usual interstitial pneumonia showing patchy fibrosis which is more prominent in the subpleural regions (lower). Focal honeycomb change is present (left lower). Note the presence of some entirely normal lung tissue (upper). h) Low-power view showing numerous vague nodular lesions involving the lung parenchyma. One of these (upper centre) is a lesion of Langerhans' cell histiocytosis, whereas the others represent respiratory bronchiolitis. Numerically, the latter were much more numerous and most likely accounted for this patient's clinical signs and symptoms (i.e. RBILD). Additional fields in this same case showed large zones with airspace filling by macrophages, typical of DIP. 
Table 1. - Clinical features of smoking-related interstitial lung diseases*

\begin{tabular}{|c|c|c|c|c|}
\hline & DIP & RBILD & PLCH & IPF \\
\hline Smoking & $90 \%$ & $100 \%$ & $>90 \%$ & $41-83 \%$ \\
\hline Age & 3 rd -5 th decades & 3rd-5th decades & 3 rd and 4th decades & Middle-aged and older \\
\hline Sex M:F & Nearly 2:1 & Slight male dominance & $1: 1$ & $1: 1$ to $2: 1$ \\
\hline Occurrence in children & Rare & No & Rare & Rare \\
\hline Onset & Insidious & Insidious & Insidious & Insidious \\
\hline Presenting symptoms & Dyspnoea, cough & Dyspnoea, cough & Dyspnoea, cough & Dyspnoea, cough \\
\hline Crackles & $60 \%$ & $\sim 50 \%$ & Usually absent & Nearly all \\
\hline Clubbing & Nearly $50 \%$ & Rare & Rare & $50-70 \%$ \\
\hline Chest radiograph & $\begin{array}{l}\text { Interstitial, patchy } \\
\text { ground-glass }\end{array}$ & $\begin{array}{l}\text { Interstitial or } \\
\text { normal }\end{array}$ & $\begin{array}{l}\text { Interstitial/cystic or } \\
\text { nodular, with basilar } \\
\text { sparing }\end{array}$ & $\begin{array}{l}\text { Interstitial, honeycombing } \\
\text { with basilar } \\
\text { predominance }\end{array}$ \\
\hline HRCT & $\begin{array}{l}\text { Ground glass with } \\
\text { lower lung } \\
\text { predominance }\end{array}$ & $\begin{array}{l}\text { Patchy ground } \\
\text { glass }\end{array}$ & $\begin{array}{l}\text { Nodules and cysts; } \\
\text { basilar sparing }\end{array}$ & $\begin{array}{l}\text { Subpleural honeycombing } \\
\text { basilar predominance }\end{array}$ \\
\hline Pulmonary function & Restrictive & $\begin{array}{l}\text { Mixed defect or } \\
\text { normal }\end{array}$ & $\begin{array}{l}\text { Obstructive or } \\
\text { restrictive }\end{array}$ & Restrictive \\
\hline Treatment & $\begin{array}{l}\text { Smoking cessation, } \\
\text { steroids }\end{array}$ & Smoking cessation & $\begin{array}{l}\text { Smoking cessation, } \\
\text { steroids? }\end{array}$ & $\begin{array}{l}\text { Steroids? Cytotoxic drugs? } \\
\text { Antifibrotic drugs? }\end{array}$ \\
\hline Response to steroids & Good & Good & Fair & Poor \\
\hline Prognosis & Good & Good & Good & Poor \\
\hline $\begin{array}{l}\text { Complete recovery } \\
\text { possible }\end{array}$ & Yes & Yes & Yes & No \\
\hline
\end{tabular}

*: Modified from KATZENSTEIN [9]. DIP: desquamative interstitial pneumonia; RBILD: respiratory bronchiolitis-associated interstitial lung disease; PCLH: pulmonary Langerhans' cell histiocytosis; IPF: idiopathic pulmonary fibrosis.

appearance at low magnification is relatively uniform from one field to another. Alveolar septa are thickened to a variable degree by diffuse fibrosis and mild interstitial inflammation. Honeycomb change, if present, is minimal, and the overall architecture is maintained although some emphysematous change is common.

The average age at onset of symptoms for patients with DIP (table 1) is $\sim 40$ yrs $[10,11]$. Occurrence in children is rare but DIP is one of the more common forms of interstitial lung disease in this age group, where it is probably a different disease not related to smoking [12, 13]. Most studies have noted a male predominance, with males affected nearly twice as often as females [9-11]. Dyspnoea and cough are the most common presenting complaints, and the onset is usually insidious. Inspiratory crackles are heard in $60 \%$ of affected patients $[10,11]$, and digital clubbing occurs in nearly one-half of patients $[10,11]$.

In the two largest case series, about $90 \%$ of patients with DIP smoked or had smoked cigarettes [10, 11]. DIP may occasionally be seen in association with systemic disorders or infections, as well as exposures to occupational/environmental agents and drugs [10-22]. For example, in the series of 40 patients with DIP reported by CARRINGTON et al. [10], 5 (12.5\%) had connective tissue diseases including one case of isoniazid-induced lupus syndrome. Only "idiopathic" cases with no associated disorders would be currently accepted as DIP. In addition, focal macrophage accumulation, termed "DIP-like reaction" may be seen as an incidental lesion in a number of settings [23, 24].

Radiographically, lung volume appears reduced unless there is coexisting obstructive airway disease such as in smokers with emphysema $[10,11]$. Bibasilar opacities of hazy, ground-glass appearance are present in about one-quarter of patients. Although this radio- graphic appearance was considered a characteristic feature of DIP in earlier reports, subsequent studies more often showed a nonspecific linear or reticulonodular interstitial pattern [9]. Restrictive defects with a decreased diffusion capacity are commonly found on pulmonary function testing, but abnormalities are usually less marked than those observed in cases of usual interstitial pneumonia [9, 10].

The predominant finding by high-resolution computed tomography (HRCT) (fig. 2) is the presence of areas of ground-glass attenuation [25, 26]. These typically have a subpleural and lower lung zone predominance. Irregular lines of attenuation suggestive of fibrosis are seen in one-half of patients and honeycombing is not usually present [25-28].

When left untreated, about two-thirds of patients with DIP have evidence of clinical worsening [10]. However, spontaneous improvement can be seen and was observed in seven $(21.9 \%)$ of 32 untreated patients with DIP reported by CARRINGTON et al. [10]. Whether improvement was related to smoking cessation is unclear. When treated, patients with DIP usually receive long-term corticosteroid therapy. Most patients with DIP remain stable or improve with corticosteroid therapy and complete recovery is possible $[10,11,27$, 28]. The response to corticosteroid therapy is not uniform and approximately one-quarter of patients may continue to worsen despite treatment for DIP [10, $11,28]$. The role of cytotoxic and other immunosuppressive agents remains undefined. In the case series reported by CARRINGTON et al. [10], $11(27.5 \%)$ of 40 patients died after an average survival of 12 yrs. Late relapse [29] as well as recurrence in transplanted lung has been reported $[30,31]$. These reports do not specify whether smoking was a factor in the recurrence of DIP. The roles of the above therapies need to be reassessed relative to the effect of smoking cessation. 
a)

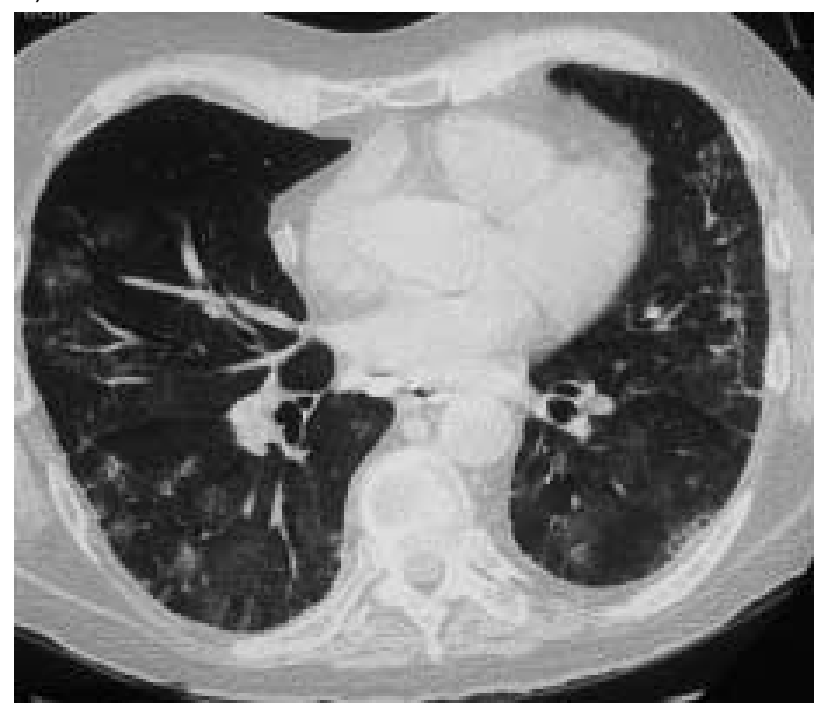

C)

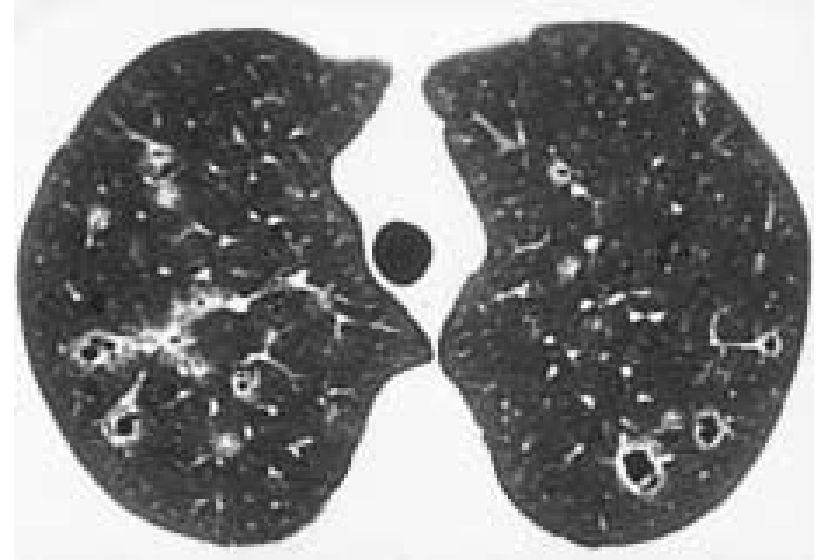

b)

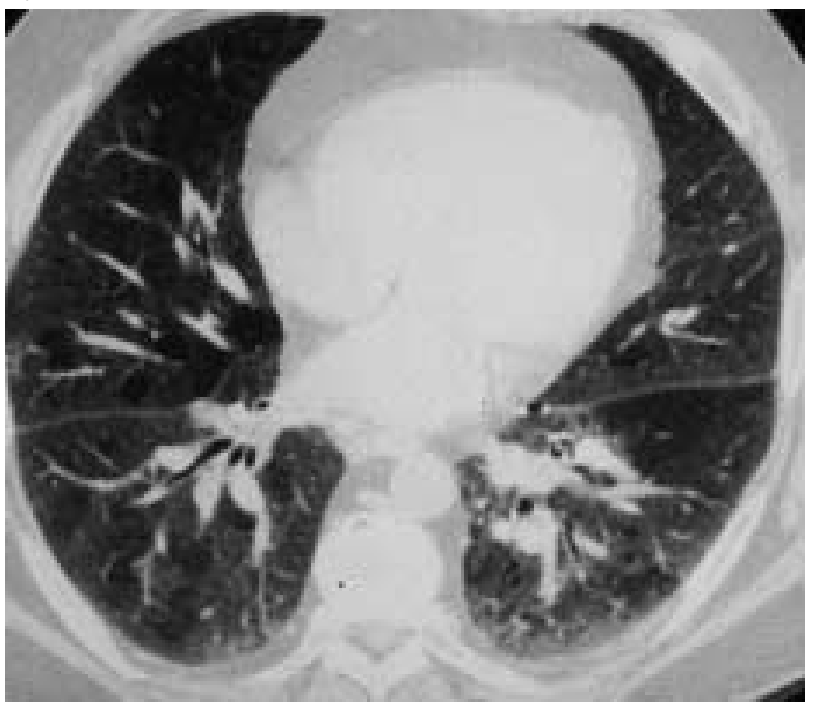

d)

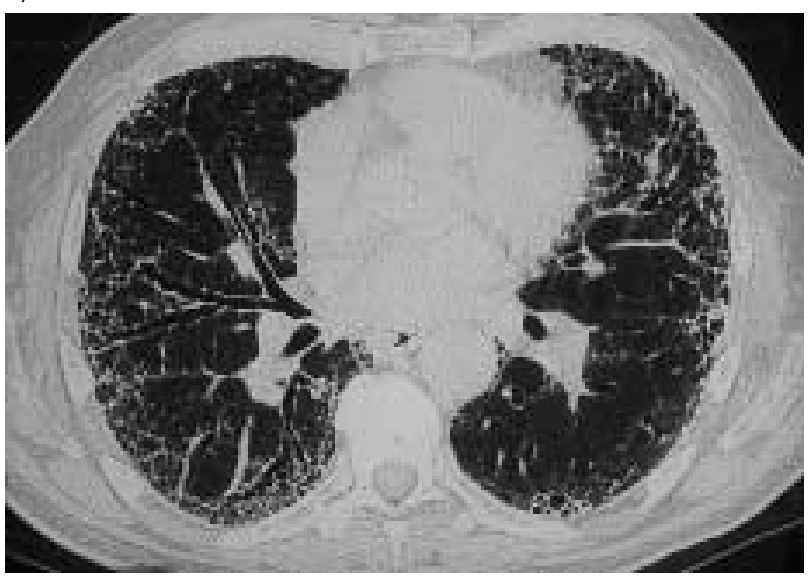

Fig. 2. - Radiological features of smoking-related interstitial lung diseases on high-resolution computed tomography (HRCT). a) HRCT of a 59-yr-old male with desquamative interstitial pneumonia showing patchy areas of ground-glass attenuation with a peripheral predominance. b) HRCT of a 51-yr-old male with respiratory bronchiolitis-associated interstitial lung disease showing patchy areas of ground-glass attenuation diffusely throughout both lungs. c) HRCT of a 33-yr-old female with pulmonary Langerhans' cell histiocytosis showing multiple nodules and thick-walled cysts. There was sparing of the lung bases (figure not shown). d) HRCT of a 72yr-old male with idiopathic pulmonary fibrosis (usual interstitial pneumonia) showing subpleural reticular densities and honeycombing with associated traction bronchiectasis.

\section{Respiratory bronchiolitis-associated interstitial lung disease}

Bronchiolitis is a generic term used clinically to describe various inflammatory diseases of small airways [32]. Bronchiolar diseases can be caused by cigarette smoke, infections, aspiration, inhalation of environmental agents, drugs, and underlying systemic disorders including connective tissue diseases and transplant rejection. Respiratory bronchiolitis was described by NiEWOEHNER et al. [33] as an incidental autopsy finding, primarily in young male smokers. This disorder is now recognized as extremely common in cigarette smokers, and the term "smoker's bronchiolitis" is descriptively appropriate [32]. Respiratory bronchiolitis usually occurs without symptoms or significant accompanying interstitial lung disease. It may account for subclinical radiological changes in up to one-fifth of smokers (see later).

Whereas respiratory bronchiolitis occurs in virtually all smokers and is of little clinical significance in the vast majority of cases, in a small portion of smokers, symptomatic interstitial lung disease may occur in association with this lesion. In 1987, MYERS et al. [34] described what was subsequently labeled respiratory bronchiolitis-associated interstitial lung disease (RBILD). This is a clinicopathological entity seen almost exclusively in current or former cigarette smokers and may be confused with other interstitial lung diseases, in particular, IPF [11, 34-36].

RBILD is characterized by the presence of pigmented macrophages and mild interstitial inflammatory changes centring on respiratory bronchioles and neighbouring alveoli (fig. 1) [11, 32, 34]. Alveolar 
septa in the peribronchiolar region may be mildly thickened but without fibrosis. Similar pathological findings have been reported in patients with other inhalational injuries, especially asbestos and nonasbestos mineral dust exposure, as well as other conditions [36], but numerically such cases are rare and nearly all cases of respiratory bronchiolitis are due to smoking.

The histological distinction between RBILD and DIP is based primarily on the extent of the inflammatory process. Histopathological changes are more extensive and diffuse in DIP as compared to RBILD $[9,11,32,34]$. In RBILD, macrophage accumulation is confined to peribronchiolar airspaces with sparing of more distal airspaces. Interstitial thickening accompanies the airspace changes in RBILD and tends to be limited to the peribronchiolar parenchyma.

For the majority of patients with RBILD, the onset of symptoms is usually in the fourth or fifth decades of life $[11,34,36]$ and is considerably earlier (table 1 ) in patients with usual interstitial pneumonia (UIP) [9]. There is a slight male predominance $[11,34,36]$. Patients with RBILD commonly present with cough and dyspnoea $[11,34,36]$. These symptoms are generally mild but may at times be severe [38]. Auscultation of the lungs reveals inspiratory crackles in about half of patients [11, 36, 39]. Digital clubbing is occasionally seen $[36,38]$.

Pulmonary function results may be normal but more commonly show a mixed obstructive-restrictive pattern of a mild-to-moderate degree [11, 34, 36]. Reduced diffusing capacity is also common [11, 34, 36]. Total lung capacity maybe normal, mildly increased or mildly reduced $[11,34,36]$.

Chest radiographs are usually abnormal [11, 34, 36]. Diffuse, fine reticular or reticulonodular opacities are present in over two-thirds of patients with RBILD [11, $34,36]$. Normal chest radiographs were noted in five $(28 \%)$ of 18 patients reported by YousEm et al. [11]. Ground-glass pattern may be the predominant abnormality seen in some patients [36]. RBILD can usually be distinguished from IPF on the chest radiograph by the absence of honeycombing.

HRCT findings in RBILD have been reported in some cases. Areas of ground-glass attenuation are the most common finding (fig. 2), but fine nodules may also be seen [26, 36, 40, 41]. Associated emphysematous changes may be present, but signs of IPF, such as subpleural honeycombing and traction bronchiectasis, are absent. It has been postulated that the areas of ground-glass attenuation reflect "smoker's alveolitis", whereas the micronodules represent respiratory bronchiolitis $[26,40]$. An increasing number of cases of RBILD are being recognized due to wider use of HRCT.

Patients with RBILD have a generally good prognosis, particularly with smoking cessation [11, 34, 36]. Most patients either improve or remain stable, and no deaths have been attributed to $\operatorname{RBILD}[11,34,36]$. Progressive fibrosing lung disease does not occur in patients with RBILD. Corticosteroid therapy has been employed in a few anecdotal cases and was associated with beneficial results [34]. Some of these treated patients were initially thought to have DIP [11]. However, corticosteroid therapy has little role in the management of most patients with RBILD. Smoking cessation is the most important therapeutic manoeuvre in the treatment of RBILD [11, 34, 36].

There are similarities between RBILD and DIP with respect to demographics, clinical features, and radiological features (table 1). In addition, overlapping histopathological patterns of RBILD and DIP can be seen in some patients and the term "smoking related interstitial lung disease" has been suggested for these cases [36]. The lack of a sharp histological distinction between the two lesions suggests that RBILD and DIP probably represent different ends of a spectrum of the same disease caused by the same agent, namely cigarette smoke $[9,26,36]$.

\section{Pulmonary Langerhans' cell histiocytosis}

Histiocytic disorders comprise an uncommon and confusing group of clinicopathological syndromes that are characterized by the proliferation of cells of either macrophage or dendritic cell (including Langerhans' cell) lineage [42, 43]. In 1997, the Reclassification Working Group of the Histiocyte Society categorized histiocytic disorders into two main subgroups: disorders of varied biological behaviour and malignant disorders [42]. Each category is further subdivided according to whether the abnormal cells are derived from the dendritic cell or macrophage lineage. Langerhans' cell histiocytosis ( $\mathrm{LCH}$ ) was classified as a dendritic cell-related disorder of varied biological behaviour (nonmalignant) category and includes disorders with a wide scope of severity ranging from selflimited to lethal disease. $\mathrm{LCH}$ includes several disorders that are characterized by excessive proliferation of Langerhans' cells and are defined pathologically by the presence of destructive infiltrates containing Langerhans' cells. Diffuse involvement of multiple visceral organs, associated with severe constitutional symptoms and a poor prognosis, occurs most frequently in infants (Letterer-Siwe disease). Multifocal involvement of two or more tissues, with a predilection of lesions in bone plus skin, liver, spleen, lung, hypothalamus, and/or lymph nodes, is usually encountered in children (HandSchuller-Christian syndrome). Lesions confined to a single tissue, especially bone, skin and/or lung, can occur at any age (eosinophilic granuloma).

Langerhans' cells are distinguished from dendritic cells by their characteristic penta-laminar plate-like cytoplasmic organelles (Birbeck granule or X-body) seen by electron microscopy and their strong expression of the CD1a antigen on the cell surface $[44,45]$. They also stain with S-100 antibody [45]. Langerhans' cells are present in the normal lung and have potent antigen presenting capabilities [44, 45]. Cigarette smoking is associated with accumulation of Langerhans' cells on the epithelial surface of the respiratory tract [46].

Lung involvement in LCH usually occurs in isolation, rarely as part of a systemic disease (usually in children and not associated with smoking) [47-49]. The isolated pulmonary form of $\mathrm{LCH}$ in adults occurs almost exclusively in cigarette smokers [44, 47, 48]. $\mathrm{PLCH}$ has also been referred to as primary pulmonary histiocytosis $\mathrm{X}$, pulmonary eosinophilic granuloma, and pulmonary Langerhans' cell granulomatosis, and it 
is usually classified among interstitial lung diseases of unknown origin. Although certain forms of $\mathrm{LCH}$ probably represent monoclonal proliferations of Langerhans' cells [50], it is yet unknown whether this is true of the isolated pulmonary form of $\mathrm{LCH}$ occurring in adults. It appears more likely that adult PLCH represents a polyclonal, reactive disorder triggered by cigarette smoking [51].

The characteristic histopathological finding in PLCH (fig. 1) is the presence of nodular sclerosing lesions containing Langerhans' cells accompanied by mixed cellular infiltrates [45]. The nodular lesions are poorly defined and are distributed in a bronchiolocentric fashion with intervening normal lung parenchyma. The presence of Langerhans' cells is required for definitive diagnosis. As the lesions evolve, there is fibrosis and progressive involvement of adjacent lung tissue with associated pericicatricial airspace enlargement accounting for the concomitant cystic changes.

Pathological findings vary with the stage: in the early stages, numerous Langerhans' cells accumulate in areas adjacent to terminal or respiratory bronchioles [45]. These cells appear to invade the bronchiole, destroying the bronchiolar wall in an eccentric fashion. Central cystic changes in the nodules (also called cavitation) can sometimes be traced to ectatic, destroyed small airways. Lymphocytes, alveolar macrophages and eosinophils are also present, usually at the periphery of the lesions. Inflammatory cell infiltrates may produce thickening of the alveolar walls in areas adjacent to bronchiolar lesions and the number of Langerhans' cells diminishes. As lesions heal, cellular infiltrates become less prominent and fibrosis supervenes, resulting in the typical stellate scar. Biopsy at this stage shows no Langerhans' cells. In addition, traction emphysema of alveoli adjacent to the stellate scars and peribronchiolar fibrosis is commonly observed. Central cystic change in the nodules and adjacent traction emphysema probably both account for the cystic change seen with HRCT [52]. Emphysema and respiratory bronchiolitis are usually also present away from the nodular lesions of PLCH.

Most patients are young adults in their third and fourth decades of life [45, 53-57]. Overall, the sex distribution is approximately equal [45, 53-57]. Several studies have consistently shown $>90 \%$ of patients with PLCH to be current or previous cigarette smokers [45, 53-57]. In addition, smoking has been demonstrated to be a strong risk factor for the development of PLCH in a case-control study [58]. The bronchiolar distribution of the pathological lesion is consistent with the possibility that an inhaled antigen is involved in the pathogenesis of this disorder.

Patients with PLCH commonly present (table 1) with dyspnoea $(35-87 \%)$ and cough $(50-70 \%)[45,52-$ 55]. A history of pneumothorax is obtained in $\sim 10 \%$ of patients $[45,53-56]$. Other symptoms may include wheezing, fever, fatigue, weight loss, chest pain, and haemoptysis. In the early stages of the disease, up to one-quarter of affected patients may be asymptomatic or have mild, nonspecific symptoms [51, 56]. On physical examination, crackles and digital clubbing are rarely present, but wheezes may occasionally be heard $[45,51,57]$. Cystic bone lesions may be identified in about $10 \%$ of patients with PLCH and most often appear in the skull, ribs, and pelvis [45, 53, 54, 57], and some of these bone lesions may be asymptomatic with absence of pain. Bone disease may precede the development of pulmonary disease. Diabetes insipidus is reported in up to $10 \%$ of patients $[45,53,56,57]$ but this relatively high figure may be a result of selection bias.

Physical examination is frequently normal and auscultation of the lungs only occasionally reveals scattered crackles or wheezes [44, 53, 57]. In the advanced stages of the disease, only decreased breath sounds may be appreciated [53].

In patients with PLCH, typical findings on chest radiograph include nodular or reticulonodular opacities most prominent in the middle and upper lung zones [44, $45,47,49,53,55]$. There is usually sparing of the costophrenic angles and the lung volume appears normal or increased. As the disease further advances, cystic changes and bullae appear and lung volumes are increased. HRCT of the chest confirms the predominant upper lung involvement with relative sparing of the lung bases [47, 48, 59, 60]. Thin-walled cysts, nodules (with or without cavitation) or a combination of nodules and cysts may be seen (fig. 2). Reticular densities and areas of ground-glass attenuation are uncommon [60, 61]. The shape of the cysts may be irregular and more complex compared to those seen in pulmonary lymphangiomyomatosis. The sparing of the lung bases is also an important finding in differentiating PLCH from pulmonary lymphangiomyomatosis [59].

Both obstructive and restrictive changes may be seen in patients with $\mathrm{PLCH}$. The effects from cigarette smoking may be superimposed and difficult to distinguish from the effects of PLCH itself. Diffusing capacity is usually abnormal [44, 45, 53, 54]. Exercise performance is commonly impaired and may reflect pulmonary vascular dysfunction [54, 62, 63].

The diagnosis of PLCH may be strongly suspected based on epidemiological, clinical, radiographical, and physiological features. Diffuse interstitial opacities, predominant in mid- and upper lungs with normal or increased lung volume seen by chest radiography in a young adult smoker, strongly suggest the diagnosis of PLCH in the absence of occupational or environmental exposure. The features seen on the HRCT, when typical, are diagnostic for this disorder [59]. Absence of a cigarette smoking history makes the diagnosis of PLCH very unlikely. For histopathological confirmation of the diagnosis, surgical lung biopsy is generally needed although transbronchial lung biopsy can be diagnostic, if adequate tissue is obtained [45, 47, 48, 53, 64]. The findings of $\geqslant 5 \%$ CD1a-positive cells (Langerhans' cells) in the bronchoalveolar lavage fluid also supports the diagnosis of PLCH [55].

Because of the wide variation in the natural history of PLCH, there are few reliable guidelines concerning treatment and prognosis. In general, the extent and severity of initial pulmonary involvement as assessed by chest radiograph and pulmonary function testing appears to have prognostic value $[45,53,55]$. Progression of the disease to advanced pulmonary fibrosis and death are uncommon [45, 53]. Although corticosteroid therapy has been used in the treatment of patients with 
PLCH, it is of unclear benefit [45, 47, 48, 53, 55, 65]. Other therapies have included cytotoxic drugs including cyclophosphamide, vinblastine, and chlorambucil. Unfortunately, none has clearly improved the course of the disease $[45,47,48,53,55]$. Pleurodesis may be needed in patients with recurrent pneumothoraces.

Definitive study of the therapeutic role for smoking cessation in patients with PLCH has not been performed. Similarly, the relationship between smoking status and progression of the disease remains to be clarified. Radiological improvement and even complete resolution of PLCH after smoking cessation has been described in case reports [66, 67]. Recurrence of PLCH in the transplanted lung has been seen in patients who resumed smoking after their lung transplantation [68]. Smoking cessation may prevent progression of the disease and should be strongly encouraged for patients with PLCH who continue to smoke.

\section{Idiopathic pulmonary fibrosis}

IPF, also called cryptogenic fibrosing alveolitis in Europe, is the most common form of interstitial lung disease $[4,69]$. The prevalence of IPF is not precisely known but has been estimated to be about 3-29 cases per 100,000 population [69]. The wide range in this estimate is probably explained by the lack of uniform definition used in identifying cases of IPF as well as differences in study designs and populations. The male to female ratio has ranged: $\sim 1: 1-2: 1[69,70]$ and patients are usually in their sixth to eighth decades of life at presentation $[4,35,71]$. Most cases of IPF are sporadic but familial forms do occur $[72,73]$.

In the early case series, the diagnosis of IPF was based on clinical/radiological findings without histological confirmation in many cases [74]. Recently, histological patterns have been more carefully defined and suggest that patients previously diagnosed to have IPF display a variety of histological patterns that are associated with varying responses to therapy and prognosis $[9,35,75]$. The most common histological pattern in cases previously diagnosed as IPF is UIP (fig. 1). IPF/UIP is associated with a worse prognosis (median survival of $\sim 3$ yrs) and relative refractoriness to corticosteroid therapy compared to other forms of chronic interstitial pneumonias including DIP, nonspecific interstitial pneumonia and bronchiolitis obliterans organizing pneumonia [35, 77-78]. The term "idiopathic pulmonary fibrosis" should now be reserved for those patients with UIP of unknown cause [35, 78].

Typical clinical features of IPF include gradually progressive exertional dyspnoea, chronic cough (usually dry) and bibasilar inspiratory ("Velcro") crackles [35, 78]. Digital clubbing is seen in about two-thirds of patients with IPF [35]. Clinical history, examination, and screening laboratory tests yield no clues as to the cause of progressive pulmonary fibrosis. In particular, environmental and occupational exposures, as well as drugs, need to be excluded as potential causes.

Chest radiography demonstrates bilateral reticular or reticulonodular opacities with small lung volumes [35, 78]. Typically, there is lower lung zone and peripheral predominance in the distribution of these infiltrates.
HRCT of the chest (fig. 2) typically shows irregular linear opacities and honeycombing, predominantly in the bases and subpleural lung [79, 80]. Areas of groundglass attenuation may be seen but are not usually extensive. When these HRCT features are present in a proper clinical context, the diagnosis of IPF is correct in $85-90 \%$ of patients $[81,82]$. However, HRCT of the chest may be normal in a small percentage of patients with biopsy-proven IPF [83]. In addition, HRCT may not distinguish chronic hypersensitivity pneumonitis from IPF in some cases [84].

Pulmonary function testing usually demonstrates a restrictive defect with reduced lung volumes and diffusing capacity $[35,78]$. The ratio of forced expiratory volume in one second to forced vital capacity (FEV1/FVC) is normal or elevated, consistent with a restrictive dysfunction. Gas exchange is usually impaired with an increased alveolar-arterial partial pressure of oxygen $\left(\mathrm{PA}-\mathrm{a}, \mathrm{O}_{2}\right)$ gradient. Even when the resting oxygen tension in arterial blood $\left(\mathrm{Pa}_{\mathrm{a}} \mathrm{O}_{2}\right)$ is normal, exercise-induced desaturation is almost always seen.

It should be noted that in patients with pre-existing emphysema, the lung volumes and flow rates may be normal due to the counteracting physiological effects of emphysema and fibrosis [85]. In such patients with coexisting emphysema and IPF, pulmonary function testing may only reveal a severely reduced diffusing capacity. HRCT will verify the coexistence of these two processes in the lung.

Histological confirmation of the diagnosis of UIP requires a surgical biopsy obtained via thoracotomy (open lung biopsy) or thoracoscopy. In recent years, video-assisted thoracoscopic (VATS) biopsy has virtually replaced open lung biopsy in the evaluation of patients with interstitial lung diseases $[4,86]$. Adequate and representative lung specimens obtained in this fashion will provide the information regarding the nature of the underlying histological lesion and the activity of the disease. However, it is controversial as to whether every patient with suspected IPF should undergo a surgical lung biopsy. In the report by the British Thoracic Society, only $12 \%$ of the patients diagnosed to have IPF had surgical lung biopsy, while a survey of patients with IPF in Bernalillo county, New Mexico, USA, showed that $11 \%$ had surgical lung biopsy at the time of the initial diagnosis $[69,70]$. Thus, it is clear that the diagnosis of IPF is made clinically without a surgical lung biopsy in the majority of patients. This low rate of biopsy confirmation partly reflects disappointment with currently available therapies.

Bronchoscopic (transbronchial) biopsy of the lung in patients with suspected IPF may help in excluding granulomatous processes such as sarcoidosis and hypersensitivity pneumonitis, lymphangitic carcinomatosis or lymphoma, infections, and other ILDs that have diagnostic or characteristic histopathological features that can be recognized on a small biopsy specimen [35]. However, the finding of interstitial inflammation and fibrosis on a bronchoscopic biopsy specimen is nonspecific and unreliable in the diagnosis or exclusion of UIP [87].

The mainstay of treatment for patients with IPF has been corticosteroid therapy, which is of unproved 
efficacy $[35,88]$. Most of the studies on the treatment of IPF have been retrospective, uncontrolled trials [35, 88]. In addition, only a few studies adequately identified the underlying histological lesions in patients with IPF [9, 35]. CARRINGTON et al. [10] noted spontaneous improvement in none of their 53 patients with UIP and a favourable response to corticosteroid therapy in only $11.5 \%$ of treated patients. The majority of patients diagnosed to have IPF, experience progression of the disease with or without therapy, resulting in cor pulmonale and respiratory failure $[10,35,89]$. In recent years, there has been increasing interest in antifibrotic therapy with agents such as colchicine and pirfenidone $[35,90,91]$. Lung transplantation should be considered early, since the waiting period for a lung transplant may be 1-2 yrs [92].

A relationship between cigarette smoking and pulmonary fibrosis has been suspected for many years [93]. The prevalence of current or previous smokers in series of IPF varies depending on the case definition used in identifying IPF cases and has ranged from $41-83 \%$ [10, 69, 74-77, 94, 95]. In some of these studies, confirmation of the diagnosis of IPF by surgical lung biopsy was not required [70, 74, 94]. BAUMGARTNER et al. [94] found a history of smoking to be associated with an increased risk of developing IPF, with an odds ratio of 1.6. In their report, slides from surgical lung biopsy specimens were available for review in less than onehalf of the study subjects [94].

The association between pulmonary fibrosis and lung cancer risk has been debated [96]. HuBBARD et al. [97] recently described a population-based cohort study in which the incidence of lung cancer was increased in patients with IPF, independent of the effect of cigarette smoking. On balance, however, the evidence is conflicting regarding this point and additional studies are needed [96].

\section{Conclusions}

The effects of cigarette smoking on the development of interstitial lung diseases are poorly understood. Due to the rarity of some of these interstitial lung diseases, it is difficult to firmly establish a direct causative role for smoking in the pathogenesis of these diseases. Nonetheless, available epidemiologic data suggest that cigarette smoking is causally related to the development of certain interstitial lung diseases, including RBILD, DIP, and PLCH (table 2). The preponderance of smokers has been consistently observed in the reported case series of patients with these disorders. In these patients, smoking cessation may prove to be the most important and effective therapeutic option and should be strongly encouraged. These lesions have also been seen as incidental findings in smokers at autopsy [33, 98]. A direct role for cigarette smoke in the pathogenesis of RBILD, DIP, and PLCH is further suggested by radiographical and clinical improvement that sometimes occurs following smoking cessation. Common causality is also suggested by the presence of combinations of these lesions in some of these affected smokers. The authors have observed cases in which all three lesions have coexisted (fig. 1).
Table 2. - Lung diseases related to smoking

\section{Lung cancer}

Chronic obstructive pulmonary disease

Chronic bronchitis

Emphysema

Interstitial lung disease

Desquamative interstitial pneumonia

Respiratory bronchiolitis-associated interstitial lung disease Pulmonary Langerhans' cell histiocytosis

Idiopathic pulmonary fibrosis

The role of smoking in the pathogenesis of IPF is controversial. Cigarette smoking appears to increase the risk of development of IPF, but there is no convincing evidence that smoking per se directly leads to the development of IPF.

The distinction between respiratory bronchiolitisassociated interstitial lung disease, desquamative interstitial pneumonia and pulmonary Langerhans' cell histiocytosis and other forms of idiopathic interstitial pneumonias, especially idiopathic pulmonary fibrosis, has important clinical implications. In general, the prognosis for respiratory bronchiolitis-associated interstitial lung disease, desquamative interstitial pneumonia, and pulmonary Langerhans' cell histiocytosis is significantly better than with idiopathic pulmonary fibrosis. Whereas the median survival for patients with idiopathic pulmonary fibrosis is about 3 yrs, the majority of patients with respiratory bronchiolitis-associated interstitial lung disease, desquamative interstitial pneumonia, and pulmonary Langerhans' cell histiocytosis are alive 10 yrs after the diagnosis [9, 74].

\section{References}

1. American Thoracic Society. Cigarette smoking and health. Am J Respir Crit Care Med 1996; 153: 861-865.

2. Bartecchi CE, MacKenzie TD, Schrier RW. The human costs of tobacco use. N Engl J Med 1994; 330: 907-980.

3. Murin S, Hilbert J, Reilly SJ. Cigarette smoking and the lung. Clin Rev All Immunol 1997; 15: 307-336.

4. Reynolds HY. Diagnostic and management strategies of diffuse interstitial lung disease. Chest 1998; 113: 192-202.

5. Schwarz MI, King TE Jr. Interstitial Lung Disease. 3rd Edn. St. Louis, Mosby-Year book, Inc., 1998; pp. 3-30.

6. Colby TV, Swensen SJ. Anatomic distribution of histopathologic patterns in diffuse lung disease: correlation with HRCT. J Thorac Imag 1996; 11: 1-26.

7. Crystal RG, Bitterman PB, Rennard SI, Hance AJ, Keogh BA. Interstitial lung disease of unknown cause: disorders characterized by chronic inflammation of the lower respiratory tract. Part I. N Engl J Med 1984; 310: 154-166.

8. Crystal RG, Bitterman PB, Rennard SI, Hance AJ, Keogh BA. Interstitial lung disease of unknown cause: disorders characterized by chronic inflammation of the lower respiratory tract. Part II. N Engl J Med 1984; 310: 235-244.

9. Katzenstein AA, Myers JL. Idiopathic pulmonary 
fibrosis: clinical relevance of pathologic classification. Am J Respir Crit Care Med 1998; 157: 1301-1315.

10. Carrington CB, Gaensler EA, Coutu RE, FitzGerald MX, Gupta RG. Natural history and treated course of usual and desquamative interstitial pneumonia. $N \mathrm{Engl}$ J Med 1978; 298: 801-809.

11. Yousem SA, Colby TV, Gaensler EA. Respiratory bronchiolitis-associated interstitial lung disease and its relationship to desquamative interstitial pneumonia. Mayo Clin Proc 1989; 64: 1373-1380.

12. Bokulic RE, Hilman BC. Interstitial lung disease in children. Ped Clin N Am 1994; 41: 543-567.

13. Stillwell PC, Norris DG, O'Connell EJ, et al. Desquamative interstitial pneumonitis in children. Chest 1980; 77: 165-171.

14. Rawbone RG, Shaw MT, Jackson JG, Bagshawe KD. Complications of methotrexate-maintained remission in lymphoblastic leukemia. BMJ 1971; 4: 467-468.

15. Bone RC, Wolfe J, Sobonya RE, et al. Desquamative interstitial pneumonia following chronic nitrofurantoin therapy. Chest 1982; 81: 321-325.

16. Case Records of the Massachusetts General Hospital (Case 12-1993). N EngI J Med 1993; 328: 869-876.

17. Corrin B, Price AB. Electron microscopic studies in desquamative interstitial pneumonia associated with asbestos. Thorax 1972; 27: 324-331.

18. Abraham JL, Hertzberg MA. Inorganic particulates associated with desquamative interstitial pneumonia. Chest 1981; 80: Suppl. 1, 67S-70S.

19. Lougheed MD, Roos JO, Waddell WR, Munt PW. Desquamative interstitial pneumonitis and diffuse alveolar damage in textile workers: potential role of mycotoxins. Chest 1995; 108: 1196-1200.

20. Goldstein JD, Godleski JJ, Herman PG. Desquamative interstitial pneumonitis associated with monomyelocytic leukemia. Chest 1982; 81: 321-325.

21. Case Records of the Massachusetts General Hospital. (Case 5-1998). N EngI J Med 1998; 338: 453-461.

22. Kern DG, Kuhn C III, Ely W, et al. Flock worker's lung: broadening the spectrum of clinicopathology, narrowing the spectrum of suspected etiologies. Chest 2000; 117: 251-259.

23. Bedrossian CW, Kuhn C III, Luna MA, Conklin RH, Byrd RB, Kaplan PD. Desquamative interstitial pneumonia-like reaction accompanying pulmonary lesions. Chest 1977; 72: 166-169.

24. Katzenstein AA. Idiopathic interstitial pneumonia: classification and diagnosis. Monog in Pathol 1993; 36: $1-31$.

25. Hartman TE, Primack SL, Swensen SJ, Hansell D, McGuiness G, Muller NL. Desquamative interstitial pneumonia: thin-section CT-findings in 22 patients. Radiology 1993; 187: 787-790.

26. Heyneman LE, Ward S, Lynch DA, Remy-Jardin M, Johkoh T, Müller NL. Respiratory bronchiolitis, respiratory bronchiolitis-associated interstitial lung disease, and desquamative interstitial pneumonia: different entities or part of the spectrum of the same disease process? AJR 1999; 173: 1617-1622.

27. Akira M, Yamamoto S, Hara H, Sakatani M, Ueda B. Serial computed tomographic evaluation in desquamative interstitial pneumonia. Thorax 1997; 52: 333 337.

28. Hartman TE, Primack SL, Yang EY, et al. Disease progression in usual interstitial pneumonia compared with desquamative interstitial pneumonia: assessment with serial CT. Chest 1996; 110: 378-382.
29. Lipworth B, Woodcock A, Addis B, Turner-Warwick M. Late relapse of desquamative interstitial pneumonia. Am Rev Respir Dis 1987; 136: 1253-1255.

30. Verleden GM, Sels F, Van Raemdonck D, Verbeken EK, Demedts M. Possible recurrence of desquamative interstitial pneumonitis in a single lung transplant recipient. Eur Respir J 1998; 11: 971-974.

31. Barberis M, Mazari S, Tironi A, Lampertico P. Recurrence of primary disease in a single lung transplant recipient. Transplant Proc 1992; 24: 2660 2662.

32. Colby TV. Bronchiolitis: pathologic considerations. Am J Clin Pathol 1998; 109: 101-109.

33. Niewoehner D, Klinerman J, Rice D. Pathologic changes in the peripheral airways of young cigarette smokers. N Engl J Med 1974; 291: 755-758.

34. Myers JL, Veal CF Jr, Shin MS, Katzenstein AA. Respiratory bronchiolitis causing interstitial lung disease: a clinicopathologic study of six cases. $\mathrm{Am}$ Rev Respir Dis 1987; 135: 880-884.

35. Ryu JH, Colby TV, Hartman TE. Idiopathic pulmonary fibrosis: current concepts. Mayo Clin Proc 1998; 73: 1085-1101.

36. Moon J, du Bois RM, Colby TV, Hansell DM, Nicholson AG. Clinical significance of respiratory bronchiolitis on open lung biopsy and its relationship to smoking related interstitial lung disease. Thorax 1999; 54: 1009-1014.

37. Wright JL, Cagle P, Churg A, Colby TV, Myers J. State of the art: diseases of the small airways. Am Rev Respir Dis 1992; 146: 240-262.

38. Sadikot RT, Johnson J, Loyd JE, Christman JW. Respiratory bronchiolitis associated with severe dyspnea, exertional hypoxemia, and clubbing. Chest 2000; 117: 282-285.

39. King TE Jr. Respiratory bronchiolitis-associated interstitial lung disease. Clin Chest Med 1993; 14: 693698.

40. Remy-Jardin M, Remy J, Boulenguez C, et al. Morphologic aspects of cigarette smoking on airways and pulmonary parenchyma in healthy adult volunteers: CT evaluation and correlation with pulmonary function tests. Radiology 1993; 186: 107-115.

41. Holt RM, Schmidt RA, Goodwin D, Raghu G. High resolution $\mathrm{CT}$ in respiratory bronchiolitis associated interstitial lung disease. J Comput Assist Tomog 1993; 17: 46-50.

42. Favara BE, Feller AC with members of the WHO Committee on Histiocytic/Reticulum Cell Proliferations. Contemporary classification of histiocytic disorders. Med Ped Oncol 1997; 29: 157-166.

43. Cline MJ. Histiocytes and histiocytosis. Blood 1994; 84: 2840-2853.

44. Soler P, Kambouchner M, Valeyre D, Hance AJ. Pulmonary Langerhans' cell granulomatosis (Histiocytosis X). Am Rev Med 1992; 43: 105-115.

45. Travis WD, Borok Z, Roum JH, et al. Pulmonary Langerhans cell granulomatosis (Histiocytosis X): a clinicopathologic study of 48 cases. Am J Surg Pathol 1993; 17: 971-986.

46. Casolaro MA, Bernaudin JF, Saltini C, Ferrans VJ, Crystal RG. Accumulation of Langerhan's cells on the epithelial surface of the lower respiratory tract in normal subjects in association with cigarette smoking. Am Rev Respir Dis 1988; 137: 406-411.

47. Tazi A, Soler P, Hance AJ. Adult pulmonary Langerhans' cell histiocytosis. Thorax 2000; 55: 405-416. 
48. Vassallo R, Ryu JH, Colby TV, Hartman T, Limper AH. Pulmonary Langerhans'-cell histiocytosis. $N$ Engl J Med 2000; 342: 1969-1978.

49. Smets A, Mortele K, de Praeter G, Francois O, Benoit Y, Kunnen M. Pulmonary and mediastinal lesions in children with Langerhans cell histiocytosis. Ped Radiol 1997; 27: 873-876.

50. Willman CL, Busque L, Griffith BB, et al. Langerhans'-cell histiocytosis (Histiocytosis X) - a clonal proliferative disease. N EngI J Med 1994; 331: 154 160.

51. Yousem SA, Colby TV, Weiss LM. Pulmonary Langerhans' cell histiocytosis: molecular analysis of clonality. Am J Surg Pathol 2001; (in press).

52. Soler P, Bergeron A, Kambouchner M, et al. Is highresolution computed tomography a reliable tool to predict the histopathological activity of pulmonary Langerhans cell histiocytosis? Am J Respir Crit Care Med 2000; 162: 264-270.

53. Friedman PJ, Liebow AA, Sokoloff J. Eosinophilic granuloma of lung: clinical aspects of primary pulmonary histiocytosis in the adult. Medicine 1981; 60: 385-396.

54. Crausman RS, Jennings CA, Tuder RM, Ackerson LM, Irvin CG, King TE Jr. Pulmonary histiocytosis X: pulmonary function and exercise physiology. $\mathrm{Am}$ J Respir Crit Care Med 1996; 153: 426-435.

55. Basset F, Corrin B, Spencer H, et al. Pulmonary histiocytosis X. Am Rev Respir Dis 1978; 118: 811-820.

56. Delobbe A, Durieu J, Duhamenl A, Wallaert B, and the Groupe d'etude en Pathologie Interstitielle de la Société de Pathologie Thoracique du Nord. Determinants of survival in pulmonary Langerhans' cell granulomatosis (histiocytosis X). Eur Respir $J$ 1996; 9: 2002-2006.

57. Schönfield N, Frank W, Wenig S, et al. Clinical and radiologic features, lung function and therapeutic results in pulmonary histiocytosis $\mathrm{X}$. Respiration 1993; 60: 38-44.

58. Hance AJ, Basset F, Saumon G, et al. Smoking and interstitial lung disease: the effect of cigarette smoking on the incidence of pulmonary histiocytosis $\mathrm{X}$ and sarcoidosis. Ann NY Acad Sci 1986; 465: 643-656.

59. Bonelli FS, Hartman TE, Swensen SJ, Sherrick A Accuracy of high-resolution CT in diagnosing lung diseases. AJR 1998; 170: 1507-1512.

60. Brauner MW, Grenier P, Tijani K, Battesti JP, Valeyre D. Pulmonary Langerhans cell histiocytosis: evolution of lesions on CT scans. Radiology 1997; 204: 497-502.

61. Tazi A, Montcelly L, Bergeron A, Valeyre D, Battesti JP, Hance AJ. Relapsing nodular lesions in the course of adult pulmonary Langerhans cell histiocytosis. Am J Respir Crit Care Med 1998; 157: 2007-2010.

62. Benyounes B, Crestani B, Couvelard A, Vissuzaine C, Aubier M. Steroid-responsive pulmonary hypertension in a patient with Langerhans' cell granulomatosis (histiocytosis X). Chest 1996; 110: 284-286.

63. Fartoukh M, Humbert M, Capron F, et al. Severe pulmonary hypertension in histiocytosis X. Am J Respir Crit Care Med 2000; 161: 216-223.

64. Housini I, Tomashefski KF Jr, Cohen A, Crass J, Kleinerman J. Transbronchial biopsy in patients with pulmonary eosinophilic granuloma: comparison with findings on open lung biopsy. Arch Pathol Lab Med 1994; 118: 523-530.

65. Lieberman $\mathrm{PH}$, Jones CR, Steinman RM, et al. Langerhans cell (eosinophilic) granulomatosis: a clini- copathologic study encompassing 50 years. Am J Surg Pathol 1996; 20: 519-552.

66. Von Essen S, West W, Sitorius M, Rennard SI. Complete resolution of roentgenographic changes in a patient with pulmonary histiocytosis X. Chest 1990; 98: 765-767.

67. Etienne B, Bertocchi M, Gamondes JP, et al. Relapsing pulmonary Langerhans cell histiocytosis after lung transplantation. Am J Respir Crit Care Med 1998; 157: 288-291.

68. Mogulkuc N, Veral A, Bishop PW, Bayindir U, Pickering CAC, Egan JJ. Pulmonary Langerhans' cell histiocytosis: radiologic resolution following smoking cessation. Chest 1999; 115: 1452-1455.

69. Coultas DB, Zumwalt RE, Black WC, Sobonya RE. The epidemiology of interstitial lung diseases. $\mathrm{Am}$ J Respir Crit Care Med 1994; 150: 967-972.

70. Johnston IDA, Prescott RJ, Chalmers JC, Rudd RM. British Thoracic Society study of cryptogenic fibrosing alveolitis: current presentation and initial management. Thorax 1997; 52: 38-44.

71. King TE Jr. Idiopathic pulmonary fibrosis. In: Schwarz MI, King TE Jr, eds. Interstitial Lung Disease. 2nd ed. St. Louis, Mosby-Year book, Inc., 1993; pp. 367-403.

72. Barzo P. Familial idiopathic fibrosing alveolitis. Eur J Respir Dis 1985; 66: 350-352.

73. Marshall RP, Puddicombe A, Cookson WOC, Laurent GJ. Adult familial cryptogenic fibrosing alveolitis in the United Kingdom. Thorax 2000; 55: 143-146.

74. Turner-Warwick R, Burrows B, Johnson A. Cryptogenic fibrosing alveolitis: clinical features and their influence on survival. Thorax 1980; 35: 171-180.

75. Bjoraker JA, Ryu JH, Edwin MK, et al. Prognostic significance of histopathologic subjects in idiopathic pulmonary fibrosis. Am J Respir Crit Care Med 1998; 157: 199-203.

76. Nagai S, Kitaichi M, Itoh H, Nishimura K, Izumi T, Colby TV. Idiopathic nonspecific interstitial pneumonia/fibrosis: comparison with idiopathic pulmonary fibrosis and bronchiolitis obliterans organizing pneumonia. Eur Respir. J 1998; 12: 1010-1019.

77. Danil ZD, Gilchrist FC, Nicholson AG, et al. A histologic pattern of nonspecific interstitial pneumonia is associated with a better prognosis than usual interstitial pneumonia in patients with cryptogenic fibrosing alveolitis. Am J Respir Crit Care Med 1999; 160: 899-905.

78. International Consensus Statement. Idiopathic pulmonary fibrosis: diagnosis and treatment. Am J Respir Crit Care Med 2000; 161: 646-664.

79. Staples CA, Muller NL, Vedal S, Abboud R, Ostrow $\mathrm{D}$, Miller R. Usual interstitial pneumonia: correlation of CT with clinical, functional, and radiologic findings. Radiology 1987; 162: 377-381.

80. Muller NL, Miller RR, Webb WR, Evans KG, Ostrow DN. Fibrosing alveolitis; CT-pathologic correlation. Radiology 1986; 160: 585-588.

81. Mathieson JR, Mayo JR, Staples CA, Muller NL. Chronic diffuse infiltrative lung disease: comparison of diagnostic accuracy of CT and chest radiography. Radiology 1989; 171: 111-116.

82. Swensen SJ, Aughenbaugh GL, Myers JL. Diffuse lung disease: diagnostic accuracy of $\mathrm{CT}$ in patients undergoing surgical biopsy of the lung. Radiology 1997; 205: 229-234. 
83. Orens JB, Kazerooni EA, Martinez FJ, et al. The sensitivity of high-resolution CT in detecting idiopathic pulmonary fibrosis proved by open lung biopsy: a prospective study. Chest 1995; 108: 109-115.

84. Lynch DA, Newell JD, Logan PM, King TE Jr, Muller NL. Can CT distinguish hypersensitivity pneumonitis from idiopathic pulmonary fibrosis? AJR 1995; 165: 807-811.

85. Schwartz DA, Merchant RK, Helmers RA, Gilbert SR, Dayton CS, Hunninghake GW. The influence of cigarette smoking on lung function in patients with idiopathic pulmonary fibrosis. Am Rev Respir Dis 1991; 144: 504-506.

86. Harris RJ, Kavuru MS, Rice TW, Kirby TJ. The diagnostic and therapeutic utility of thoracoscopy: a review. Chest 1995; 108: 828-841.

87. Wall CP, Gaensler EA, Carrington CB, Hayes JA. Comparison of transbronchial and open biopsies in chronic infiltrative lung diseases. Am Rev Respir Dis 1981; 123: 280-285.

88. Mapel DW, Samet JM, Coultas DB. Corticosteroids and the treatment of idiopathic pulmonary fibrosis: past, present, and future. Chest 1996; 110: 1058-1067.

89. Panos RJ, Mortenson RL, Niccoli SA, King TE Jr. Clinical deterioration of patients with idiopathic pulmonary fibrosis: causes and assessment. Am J Med 1990; 88: 396-404.

90. Douglas WW, Ryu JH, Swensen SJ, et al. Colchicine versus prednisone in the treatment of idiopathic pulmonary fibrosis. Am J Respir Crit Care Med 1998; 158: 220-225.

91. Raghu G, Johnson WC, Lockhart D, Mageto Y. Treatment of idiopathic pulmonary fibrosis with a new antifibrotic agent, pirfenidone: results of a prospective open-label phase II study. Am J Respir Crit Care Med 1999; 159: 1061-1069.

92. Trulock EP. Lung transplantation. Am J Respir Crit Care Med 1997; 155: 789-818.

93. Weiss W. Cigarette smoking and diffuse pulmonary fibrosis. Am Rev Respir Dis 1969; 99: 67-72.

94. Baumgartner KB, Samet JM, Stidley CA, Colby TV, Waldron JA. Cigarette smoking: a risk factor for idiopathic pulmonary fibrosis. Am J Respir Crit Care Med 1997; 155: 242-248.

95. Perez-Padilla R, Salas J, Chapela R, et al. Mortality in Mexican patients with chronic pigeon breeder's lung compared with those with usual interstitial pneumonia. Am Rev Respir Dis 1993; 148: 49-53.

96. Samet JM. Does idiopathic pulmonary fibrosis increase lung cancer risk? Am J Respir Crit Care Med 2000; 161: 1-2.

97. Hubbard R, Venn A, Lewis S, Britton J. Lung cancer and cryptogenic fibrosing alveolitis: a populationbased cohort study. Am J Respir Crit Care Med 2000; 161: 5-8.

98. Pai U, Tomashefski JF. Occult pulmonary eosinophilic granuloma: an incidental finding in the lungs of cigarette smokers. Am J Clin Path 1993; 99: 335. 